\title{
SEGURANÇA JURÍDICA, JURISDIÇÃO E EFETIVIDADE DO DIREITO
}

\author{
LEGAL CERTAINTY, JURISDICTION AND LAW EFFECTIVENESS
}

\author{
Luciano de Araujo Migliavacca ${ }^{1}$ \\ Raquel Tomé Soveral ${ }^{2}$
}

\section{RESUMO}

Atentos à necessidade de conferir efetividade ao Direito e sendo a jurisdição um dos instrumentos aptos a reconhecer os direitos fundamentais, o presente trabalho tem como objetivo traçar um estudo sobre a prestação da tutela jurisdicional, especialmente no que tange a definição e concreção da segurança jurídica enquanto direito fundamental. Busca-se, com este ensaio, por meio da utilização do método hipotético-dedutivo, valendo-se de pesquisa bibliográfica, analisar qual a finalidade precípua da segurança jurídica, como direito fundamental estruturante do Estado Constitucional, na consecução da efetividade da jurisdição e do Direito em si.

Palavras-chave: Direito; Efetividade; Jurisdição; Segurança jurídica.

\begin{abstract}
Mindful of the need to give effect to the Law and being the jurisdiction one of the instruments able to recognize the fundamental rights, this study aims to map out a study on the provision of judicial protection, especially as regards the definition and concretion of legal certainty while fundamental right. Seeks, with this assay, through the use of hypothetical-deductive method, making use of bibliographic research, analyze what the main purpose of legal certainty as a structuring fundamental right of the Constitutional State in achieving the effectiveness of the jurisdiction and Law itself.
\end{abstract}

Keywords: Law; Effectiveness; Jurisdiction; Legal certainty.

\footnotetext{
${ }^{1}$ Doutorando em Direito pela Universidade Estácio de Sá - UNESA, São Paulo (Brasil).. Coordenador da Escola de Direito da IMED - Passo Fundo. Professor. Advogado. E-mail: lucmig@ hotmail.com

${ }^{2}$ Mestre em Direito pela Universidade de Santa Cruz do Sul - UNISC, Rio Grande do Sul (Brasil). Pós-graduada em Direito Penal e Processo Penal . Professora. Advogada. E-mail: raq_tome@ hotmail.com
} 


\section{INTRODUÇÃO}

O Estado de Direito tem como um dos pilares de sustentação o resguardo da segurança jurídica. Tal direito deriva do conceito amplo de segurança prevista pela Constituição Federal de 1988.

A segurança jurídica vincula-se às noções de certeza e previsibilidade, ou seja, revela-se imperioso que exista previsão legal para que os cidadãos possam ter ciência das consequências de qualquer de seus comportamentos, ou, no viés judicial, possibilitando conhecimento daquilo que se tem direito e o que será decidido conforme o caso concreto que se apresentar.

Igualmente, indissociável o vínculo existente entre segurança jurídica, direitos fundamentais e atuação jurisdicional, uma vez que a referida segurança possui proteção em níveis processuais já que os processos judiciais devem conferir os direitos à estabilidade, certeza, confiança e efetividade.

Ademais, a segurança aparece enquanto direito humano fundamental, tendo respaldo em documentos internacionais que tutelam os direitos humanos, bem como, especial proteção no ordenamento jurídico brasileiro, resguardado pela Constituição Federal de 1988.

Atentos à inserção da segurança jurídica enquanto um direito fundamental, e sendo um dos pilares de sustentação do Estado contemporâneo, denota-se a necessidade de sua efetivação enquanto direito a ser observado quando da prestação da tutela jurisdicional. Ainda, a própria segurança jurídica propicia a realização do Direito em si à medida em que permite a consolidação da norma historicamente.

Nesse interim, o presente ensaio, cuja metodologia trabalhada se vale de pesquisa bibliográfica - doutrinária e legislativa - tendo, portanto, como método o hipotético-dedutivo, tem como escopo realizar um estudo acerca da segurança jurídica - vinculada a noção de certeza - notadamente enquanto um direito fundamental, a fim de demonstrar a ligação existente entre a efetivação desta e prestação jurisdicional. 
Ainda, a jurisdição é um instrumento capaz de tutelar e resguardar de maneira concreta a segurança jurídica aos cidadãos, em razão disto, justifica-se a necessidade da realização deste estudo para que não se olvide a verificação da jurisdição sob a ótica da segurança jurídica no sentido de concreção deste direito fundamental.

A partir disto, pretende-se responder a problemática, na qual reside este estudo, para saber qual a finalidade precípua da segurança jurídica, como direito fundamental estruturante do Estado Constitucional, na consecução da efetividade da jurisdição e do Direito em si?

A relevância deste estudo está na existência da segurança jurídica dentro do ordenamento jurídico brasileiro enquanto um direito fundamental, bem como, na imprescindibilidade latente da efetivação destes direitos, sendo que se tem na jurisdição uma das maneiras de possibilitar a concretização da segurança jurídica.

\section{SEGURANÇA JURÍDICA: CERTEZA E PREVISIBILIDADE JURISDICIONAL}

A segurança jurídica pode ser compreendida no momento em que se espera dos processos judiciais a configuração da certeza e da previsibilidade nos seus procedimentos, uma vez que o Estado contemporâneo requer a observância destes ditames.

Reconhece-se a segurança jurídica enquanto "garantia dada ao indivíduo de que sua pessoa, seus bens e seus direitos não serão objeto de ataques violentos, ou de que, se esses ataques vierem a produzir-se, a sociedade lhe assegurará proteção e reparação" (DELOS, 1938, p. 41).

Corroborando a noção de vinculação da segurança jurídica com os conceitos de certeza e previsão, tem-se Miguel Reale (1994, p. 602), quando trabalha acerca da interrelação existente entre segurança jurídica e certeza no viés almejado pela sociedade do direito, referindo que "o princípio da certeza preside - em díade indissolúvel com o da segurança todo o evolver histórico da vigência do direito", apontando enquanto fundamentos de validade dos valores do direito a justiça, a certeza jurídica e o fim.

Portanto, uma das características do ordenamento jurídico brasileiro é a codificação do direito, sendo caracterizado pela busca em garantir segurança jurídica por meio desta, a fim de "tornar o sistema completo e mais conhecido da população e com isso garantir a 
segurança e a previsibilidade no direito", no sentido de que a codificação seria capaz de garantir certeza, segurança e previsibilidade às relações jurídicas (BARBOZA, 2014, p. 234).

Assim, a referida segurança pode ser considerada a partir da sua relação com os elementos objetivos da ordem jurídica, garantias à estabilidade jurídica, segurança nas orientações e na realização do direito, atrelada aos elementos de ordem subjetiva, como a possibilidade de previsibilidade acerca dos indivíduos sobre os efeitos jurídicos que decorrem dos atos do Poder Público, em todas as esferas dos Poderes. Inclusive porque a segurança jurídica e a certeza que o direito deve conferir compõem a estrutura do Estado Constitucional liberal, inter-relacionando as funções do Estado em aplicação das leis para a proteção da liberdade e da economia (CANOTILHO, 2003).

Humberto Ávila propõe um conceito poliédrico de segurança jurídica contemplando seus mais variados aspectos indicando-a

[...] como sendo uma 'norma-princípio que exige, dos Poderes Legislativo,
Executivo e Judiciário, a adoção de comportamentos que contribuam mais para a
existência, em benefício dos cidadãos e na sua perspectiva, de um estado de
confiabilidade e de calculabilidade jurídicas, com base na sua cognoscibilidade, por
meio da controlabilidade jurídico-racional das estruturas argumentativas
reconstrutivas de normas gerais e individuais, como instrumento garantidor do
respeito à sua capacidade de - sem engano, frustração, surpresa e arbitrariedade -
plasmar digna e responsavelmente o seu presente e fazer um planejamento
estratégico juridicamente informado do seu futuro (2012, p. 682).

Não há como dissociar a segurança jurídica da própria compreensão do Estado contemporâneo, pois este prevê a necessidade de observância dos ditames constitucionais e, com especial destaque dos direitos humanos fundamentais. Em outras palavras, refere Carlos Alberto de Oliveira (s.a, p.121) que:

[...] a própria noção de Estado Democrático de Direito, erigida a princípio fundamental da Constituição Brasileira (art. $1^{\circ}$, caput) constitui substrato capital para a segurança jurídica, na medida em que salvaguarda a supremacia da Constituição e dos direitos fundamentais, garantindo o cidadão contra o arbítrio estatal, assegurando ao mesmo tempo elementos fundantes imprescindíveis a qualquer sociedade realmente democrática $[\ldots]$.

Nessa linha, Marcelo Terra (2010) afirma que a segurança jurídica é uma das bases do Estado de Direito e que, portanto, caracteriza-se enquanto um direito fundamental, reconhecendo-se a relação intrínseca entre o reconhecimento dos direitos fundamentais e o 
Estado de Direito de modo a preservar direitos e liberdades, tanto individuais quanto coletivas, conquistadas historicamente.

Uma das formas de assegurar a observância das garantias processuais ocorre por meio da prestação da tutela jurisdicional, sendo esta mecanismo ímpar de solução de conflitos - hard $\operatorname{cases}^{3}$ ou não - aduzindo ao Poder Judiciário relevante papel na observância da supremacia constitucional e asseguração dos direitos fundamentais.

Nesse sentido, a aplicabilidade da segurança jurídica guarda respaldo em níveis processuais, pois disciplina a observância quando da realização dos processos os direitos à estabilidade, certeza, confiança e efetividade (SARLET; MARINONI; MITIDIERO, 2014). Isto, juntamente com o resguardo daquelas relações jurídicas que já se constituíram, destacando a impossibilidade de retroatividade de atos estatais (CUNHA JR, 2013).

Outrossim, a fim de desenvolver uma melhor compreensão acerca da temática proposta, cabe referir que ter segurança jurídica é estar amparado por um conjugado de condições que possibilitem o conhecimento de forma antecipada e reflexiva de todas as possíveis consequências dos seus atos (SILVA, 2005).

Assim sendo, a "segurança jurídica busca propagar o sentimento de previsibilidade em relação aos efeitos jurídicos da regulação das condutas no seio da sociedade" (BARBOZA, 2014, p. 236).

Uma das formas de conferir segurança jurídica e certeza - ideários perseguidos pelo Estado de Direito - é visualizada pelo instituto da coisa julgada, não podendo, todavia, perseguir tal segurança ao ponto de deixar escapar a justiça (THEODORO JR.; FARIA, 2002). Até mesmo porque, por meio das decisões judiciais busca-se segurança jurídica, sendo que esta acaba por residir na observância das regras processuais que regulamentam o procedimento para as tomadas de decisões (WIVIURKA, 2014).

Destarte, deve-se destacar, consoante Estefânia Barboza (2014, p. 237), que atualmente o sistema jurídico tem sido marcado pela incerteza, em decorrência da modificação estrutural quando da inserção dos direitos humanos fundamentais, pois isto alterou significativamente o papel desempenhado pela jurisdição na interpretação do direito o qual inúmeras vezes consta expresso em documentos escritos, porém não se prevê como

\footnotetext{
${ }^{3}$ Trabalhados pela doutrina de Ronald Dworkin, cuja tradução livre significa casos difíceis.
} 
será sua aplicação diante do caso concreto - bem como, das divergências nas decisões judiciais, tanto em níveis monocráticos quanto dos tribunais superiores. Contudo, mesmo tendo a noção de que ter segurança jurídica é algo inalcançável, objetiva-se reduzir, então, a insegurança jurídica a "índices aceitáveis".

Diante disto, a fim de evitar que a prestação jurisdicional seja arraigada de incerteza e insegurança, imprescindível a compreensão da segurança jurídica enquanto um direito fundamental, para que seja possível direcionar a atuação jurídica no sentido de concretização deste direito, o qual é instrumento de resguardo do Estado Democrático de Direito.

\section{A POSITIVAÇÃO DA SEGURANÇA JURÍDICA ENQUANTO DIREITO FUNDAMENTAL}

Diante da compreensão sobre a segurança jurídica, bem como, da imprescindibilidade de sua existência dentro do ordenamento jurídico brasileiro, passa-se ao estudo sobre a sua temática enquanto um direito humano fundamental.

Surge, a segurança, como bem jurídico objeto de direitos fundamentais restando contemplada na Declaração de Virgínia, na Declaração da Independência dos Estados Unidos da América, na Declaração francesa des Droits de l'Homme et du Citoyen, na Declaração Americana dos Direitos e Deveres do Homem, na Declaração Universal dos Direitos Humanos, na Convenção para a Salvaguarda dos Direitos do Homem e das Liberdades Fundamentais, no Pacto Internacional de Direitos Civis e Políticos e no Pacto de São José da Costa Rica (DIP, 2012, p. 52).

A segurança, em sua acepção ampla, "é princípio fundante do Estado constitucional brasileiro" (BARBOZA, 2014, p. 236), sendo possível encontrar a segurança inserida em âmbito constitucional explicitamente quando da leitura do preâmbulo da Constituição Federal de 1988 e, também, no seu artigo 5 quando preceitua que: "Todos são iguais perante a lei, sem distinção de qualquer natureza, garantindo-se aos brasileiros e aos estrangeiros residentes no País a inviolabilidade do direito à vida, à liberdade, à igualdade, à segurança e à propriedade [...]". Além disto, é possível identificar a preocupação constitucional com a asseguração da segurança jurídica de forma implícita - alguns exemplos serão abaixo mencionados - quando trabalha com instrumentos capazes de conferir efetividade ao direito em estudo (BRASIL, 1988, s.p.). 
Para ser possível a afirmação da segurança jurídica enquanto um direito fundamental imprescindível a compreensão acerca do que são esses direitos. Assim, os direitos trazidos em âmbito constitucional referem-se a direitos fundamentais, notadamente os direitos fundamentais correspondem aos direitos humanos que ganharam positivação pelo legislador constituinte, são, deste modo, os direitos humanos positivados nas normas constitucionais, nos tratados e nas leis (COMPARATO, 2007).

Destarte, os direitos fundamentais relacionam-se com a compreensão dos direitos humanos, estes que "aparecen como un conjunto de facultades e instituiciones que, en cada momento histórico, concretan las exigencias de la dignidad, la libertad y la igualdad humana, las cuales deben ser reconocidas positivamente por los ordenamientos jurídicos" (PEREZLUÑO, 1999, p. 48).

Esses direitos advêm dos valores reconhecidos enquanto direitos humanos, valores inerentes a toda e qualquer pessoa, mas que ganha especial destaque quando positivados no ordenamento jurídico constitucional dos Estados, pois se tornam direitos fundamentais dos cidadãos. Em outras palavras, tem-se Ingo Sarlet (2007, p. 36) quando refere que:

\footnotetext{
O termo 'direitos fundamentais' se aplica para aqueles direitos do ser humano reconhecidos e positivados na esfera do direito constitucional positivo de determinado Estado, ao passo que a expressão 'direitos humanos' guardaria relação com os documentos de direito internacional, por referir-se àquelas posições jurídicas que se reconhecem ao ser humano como tal, independentemente de sua vinculação com determinada ordem constitucional, e que, portanto, aspiram à validade universal, para todos os povos e tempos, de tal sorte que revelam um inequívoco caráter supranacional (internacional). [...] Todavia, não devemos esquecer que, na sua vertente histórica, os direitos humanos (internacionais) e fundamentais (constitucionais) radicam no reconhecimento, pelo direito positivo, de uma série de direitos naturais do homem, que, neste sentido, assumem uma dimensão pré-estatal e, para alguns, ate mesmo supra-estatal. Cuida-se, sem dúvida, igualmente dos direitos humanos - considerados como tais aqueles outorgados a todos os homens pela sua mera condições humana - mas, neste caso, de direitos não positivados.
}

Destaca-se, que a constitucionalização dos direitos fundamentais não se refere a simples previsão de princípios, pois sua incidência ultrapassa tal compreensão, representa, desta forma, a "plena positivação de direitos, a partir dos quais qualquer indivíduo poderá exigir sua tutela perante o Poder Judiciário para a concretização da democracia” (MORAES, 2011, p. 3).

No que diz respeito ao conceito de direitos fundamentais, a fim de esclarecer o posicionamento deste ensaio, mister referir que desenvolve o presente estudo com base na 
fundamentação realizada por Perez Luño - conciliando os posicionamentos de FernándezGaliano e de Peces-Barba, já que tais autores desenvolvem suas doutrinas no sentido de que os direitos humanos seriam uma "categoria prévia, legitimadora e informadora dos direitos fundamentais, assim como no reconhecimento [de forma explícita em Peces-Barba e implícita em Fernández-Galiano] de que os direitos fundamentais são uma categoria descritiva dos direitos humanos positivados no ordenamento jurídico" (PEREZ-LUÑO, 2011, p. 46-47).

Outrossim, não se pode olvidar de mencionar a referência feita por Canotilho (1992, p. 529) quando menciona a fundamentalidade dos direitos fundamentais, em consonância com Alexy, na dignidade e proteção dos direitos num sentido formal e material. Assim, para além de ser imprescindível a sua previsão dentro do ordenamento jurídico é preciso a sua efetivação, ou seja, não basta abstratamente existirem, devem ser concretizados no âmbito social.

A exigência que se faz de concreção, para além da proteção, aos direitos fundamentais desenvolve-se na necessidade de proteção da dignidade humana, em razão desta ser o núcleo intangível destes direitos e isto requer, por parte do Poder Público, atos comissivos, uma vez que a problemática dos referidos direitos não está limitada apenas quanto a sua fórmula - a lei em esfera de direitos fundamentais - mas demanda complementação, ou seja, cria a exigência de que a lei realize concretamente os direitos fundamentais (CANOTILHO, 1994).

Ultrapassada a definição a que se vincula este ensaio sobre a temática dos direitos fundamentais, colocando-os enquanto centro deles a dignidade da pessoa humana destaca-se a necessidade de efetivação de todos os demais direitos fundamentais para asseguração desta. Pode-se, neste ínterim, traçar a afirmação sobre ser a segurança jurídica um direito fundamental.

Conforme alhures mencionado, a Constituição brasileira contemporânea contempla a segurança enquanto um direito fundamental (BRASIL, 1988). Notório que não menciona explicitamente segurança jurídica, mas apenas segurança, fazendo com que a leitura seja mais ampla, denotando a existência de direitos fundamentais relacionados à segurança - pública, jurídica e social, por exemplo.

Nesse sentido, já na década de noventa, Peces-Barba (1990, p. 223) afirmava que: “[...] la seguridad jurídica em relación con el ejercicio del poder se presenta también em otros casos como derecho fundamental", ganhando especial destaque às garantias processuais, 
como o direito a um processo justo julgado por um magistrado imparcial, assegurando a defesa e a possibilidade probatória, a legalidade e o non bis in idem ${ }^{4}$, todos esses exemplos referidos pelo autor enquanto concretizadores da segurança jurídica e referem-se a direitos fundamentais.

Igualmente, Ingo Sarlet (2006, p. 4) afirma que a segurança jurídica deflagra um lugar ímpar na ordem jurídico-constitucional brasileira, pois faz parte dos elementos nucleares que contornam o Estado de Direito, direito indissociável da Constituição de 1988.

Ademais, tem-se Perez-Luño (2000, p. 28), corroborando ao posicionamento deste trabalho de assumir a segurança jurídica enquanto um direito fundamental, direito este essencial à asseguração do todos os demais direitos da Constituição, quando explicita que:

En el Estado de Derecho a seguridad jurídica asume unos perfiles definidos como: presupuesto del Derecho, pero no de cualquier forma de legalidad positiva, sino de aquella que dimana de los derechos fundamentales, es decir, los fundamentan em enterro orden constitucional; y función del Derecho que assegura la realización de las libertades. Com ello, la seguridad jurídica no sólo se inmuniza frente al riesgo de su manipulación, sino que se convierte em um valor jurídico ineludible para el logro de los restantes valores constitucionales.

Ademais, diante da leitura dos dispositivos constitucionais verifica-se o resguardo deste direito a fim de conseguir conferir sua concretização, em diversos incisos do artigo $5^{\circ}$ : inciso II - refere-se à legalidade, onde nenhuma pessoa será obrigada a fazer algo que não esteja previsto em lei, nem será punido por ter feito algo que não exista lei antevendo devida sanção, relacionando a leitura com o inciso XXXIX -; inciso XXXVI - dispõe sobre o respeito às decisões definitivas e aos direitos adquiridos -; inciso XL - proibindo a retroatividade da lei penal, salvo em benefício ao agente da conduta delituosa -; inciso XLVI - que assegura a individualização da pena -; inciso LIV - que dispõe sobre a necessidade de observação do devido processo legal-; inciso LV - refere o direito ao contraditório e à ampla defesa em âmbito processual; inciso LXV - que prevê o relaxamento das prisões ilegais (BRASIL, 1988).

\footnotetext{
${ }^{4}$ Tradução livre: não repetir sobre o mesmo. Tal princípio, especialmente aplicado na esfera penal, significa que uma pessoa não poderá ser punida duas vezes considerando a mesma situação.
} 
Cumpre referir que "nem o princípio fundamental da segurança jurídica e nem mesmo o complexo dos direitos fundamentais [...] [que vislumbram-se na Constituição], esgotam o elenco de possibilidade quando se cuida de delimitar o âmbito de proteção de um direito à segurança jurídica" (SARLET, 2006, p. 6-7).

Em nível internacional verifica-se, igualmente, a previsão e inserção da segurança jurídica enquanto direito humano fundamental, de forma implícita com a previsão de algumas garantias que denotam a finalidade da segurança jurídica, como, por exemplo, o artigo $9^{\circ}$ da Convenção Americana dos Direitos Humanos (1969, s.p.) e o artigo $3^{\circ}$ da Declaração dos Direitos Humanos da ONU (1948, s.p.). Nesse mesmo ínterim - de que este direito é contemplado em nível de algumas garantias e não explicitamente, vem Ingo Sarlet (2006, p.4), quando afirma que "[no] plano internacional, por sua vez, verifica-se que os principais documentos em matéria de reconhecimento e proteção dos Direitos Humanos Fundamentais não contém referência expressa a um direito à segurança jurídica como tal”.

Apesar de não existir uma menção expressão de segurança jurídica, é possível verificar que para a existência do Estado democrático de direito, ou seja, para a efetivação dos direitos fundamentais, não há como esquivar-se da afirmação de ser a segurança jurídica um direito fundamental, do contrário haveria despotismo. Nesse sentido:

\footnotetext{
Certo é que havendo, ou não, menção expressa a um direito à segurança jurídica, de há muito, pelo menos no âmbito do pensamento constitucional contemporâneo, se enraizou a idéia de que um autêntico Estado de Direito é sempre também - pelo menos em princípio e num certo sentido - um Estado da segurança jurídica [...] Com efeito, a doutrina constitucional contemporânea, de há muito e sem maior controvérsia no que diz com este ponto, tem considerado a segurança jurídica como expressão inarredável do Estado de Direito, de tal sorte que a segurança jurídica passou a ter o status de subprincípio concretizador do princípio fundamental e estruturante do Estado de Direito. Assim, para além de assumir a condição de direito fundamental da pessoa humana, a segurança jurídica constitui simultaneamente princípio fundamental da ordem jurídica estatal e, para além desta, da própria ordem jurídica internacional (SARLET, 2006, p. 5).
}

Ademais, tal direito é estabelecido enquanto um valor que perfaça a própria condição da razão de existirem outros valores, sendo o fundamento para o exercício dos direitos e o desenvolvimento da ordem e da certeza (PARGA, 1999).

Vinculando-se a noção de segurança jurídica com a própria noção de direitos naturais, referindo-se que a segurança jurídica está estampada enquanto a própria finalidade do direito, possibilitando alcançar o objetivo da justiça material - razão de ser do direito natural. Evolutivamente, a segurança jurídica dentro do constitucionalismo do Estado social, 
em razão da influência das matrizes democráticas, amplia seu campo de abrangência, direcionando a existência de segurança dos indivíduos com o poder estatal, bem como, nas relações horizontais individuais. Deste modo, a segurança se faz presente no seio social demonstrando a relação do cidadão com as necessidades sociais e, especialmente, a efetividade destes interesses (PECES-BARBA, 1990).

Não é recente a afirmação e o reconhecimento de que a segurança jurídica encontrase no ordenamento jurídico constitucional brasileiro enquanto um direito fundamental, ganhando relevância ímpar quando inúmeros outros direitos fundamentais existem com a finalidade, igualmente, de conferir observância ao direito a um processo jurisdicional que traga justiça e certeza aos envolvidos.

Neste sentido, a atuação do Poder Judiciário assume relevante participação no tocante a significação e concretização dos direitos humanos, a fim de que seja possível ter-se um paradigma de segurança jurídica para além da limitação textual (BARBOZA, 2014).

Assim sendo, tão importante quanto existir formalmente a previsão para que a segurança jurídica seja observada, são os mecanismos que existem capazes de conferir a efetividade necessária a tais direitos - humanos fundamentais - pois de nada serve um direito formalmente reconhecido se quando da sua aplicação se esquecesse de concretizá-lo. A partir disto, surge a ideia do presente ensaio em analisar a existência de instrumentos concretizadores do direito fundamental à segurança jurídica advindos com a novel previsão legal do processo civil.

\section{A EFETIVIDADE DA SEGURANÇA JURÍDICA}

A segurança jurídica deve exercer sua função precípua, enquanto direito fundamental, ressaltando a importância da efetividade do direito de modo a superar o dogmatismo legalista sendo passível de aplicação de realização do res iusta ${ }^{5}$.

Assim, a referida segurança não pode resumir-se à regularidade estrutural e funcional do sistema jurídico (PEREZ-LUNO, 1991, p. 21) posto que, conforme Ricardo Dip (2012, p.

\footnotetext{
5 Tradução livre: coisa justa.
} 
23), "tratar-se-ia, exclusivamente, então, de uma sobrevivência formal, sem comprometimento com a substância do sobrevivo".

Nesse contexto, atribui-se ao processo

a função primária de codificar a relação fundamental entre a iniciativa do indivíduo para a instauração do processo (princípios dispositivo e da demanda) e a possibilidade de se obter em juízo uma tutela jurisdicional adequada (adequação, ver-se-á depois, significa proporcionalidade entre efetividade e segurança) (OLIVEIRA, 2008, p. 17).

Reconhecendo a tensão existente entre a efetividade e a segurança jurídica, Fernando Rubin (2015, p. 6), erigindo-os a macroprincípios processuais, destaca que ambos são "responsáveis por determinar a adequada e lógica marcha do processo, tendente à pacificação das relações estremecidas e formação de decisão com o selo do Estado com interessante caráter prospectivo".

Guilherme Rizzo do Amaral (2011, p. 240), ao invés de conceituar como macroprincípio, elenca efetividade e segurança jurídica como complexos valorativos

pois abrigam elementos que também podem ser designados de valores em suas esferas de atuação. Assim, por exemplo, o complexo valorativo da efetividade abriga valores como economia processual, celeridade e aproveitamento dos atos processuais. Já o complexo valorativo da segurança engloba a previsibilidade, a confiança legítima nos atos da administração e atos estatais em geral, o respeito ao direito positivo, a dignidade da legislação e a estabilidade das relações jurídicas.

Sob outro enfoque, Terra (2010, p. 124) afirma que se pode encarar a segurança jurídica sob dois enfoques: o primeiro concernente à certeza, resultante do inequívoco saber do conteúdo de uma norma jurídica, e o segundo que diz respeito à eficácia no tempo, decorrente da confiabilidade acerca da impossibilidade de que uma nova norma jurídica ou uma nova interpretação judiciária ou administrativa de uma velha norma jurídica retroagirão.

Compreende-se, assim, que a segurança jurídica deve se revestir de função maior que apenas a estabilidade ou a definição da "certeza do direito", valores externados na conceituação da mesma, eis que

é que o direito positivo tem por fim o bem comum, que não se inclina somente à realização do justo em concreto, senão que, não o perdendo de vista, embora, tende também à segurança jurídica. Quando, portanto, as leis se revelam ineficazes, não só se adverte um risco para a consumação do ato justo, mas também o perigo de turbarse, objetivamente, a segurança e, subjetivamente, a certeza do direito (DIP, 2102, p. 57). 
Mitidiero (2013, p. 17), discorrendo sobre a dignidade da pessoa humana e a segurança jurídica como fundamento do Estado Constitucional, reconhece que a tutela dos direitos representa a finalidade do processo civil, viabilizando "condições institucionais para autodeterminação da pessoa e desenvolvimento da vida social em circunstâncias de mútua confiança” (MACCORMICK, 2015, p, 16).

Assume o processo meio para tutela efetiva dos direitos, não sendo possível admitir a sua imposição tendente a padronizar, instrumental e procedimentalmente, decisões sob pena de se inferir apenas um aspecto da segurança jurídica, capaz de gerar verdadeira injustiça.

A "estandartização" decisionista é contrária ao ideal de segurança jurídica eis que a mesma serve à efetividade do Direito e não apenas para, através de um critério reducionista, aplicar a mesma decisão para casos idênticos. Deve-se conceber a segurança jurídica como algo diverso da manutenção cega e indiscriminada do status quo, como pugna Oliveira (2006, p. 262). Reconhece-se que "a segurança jurídica, nesse contexto, visa garantir o nível necessário de formalidade e flexibilidade para alcançar a efetividade sem que prejudique as demais garantias processuais" (CAMBI; BUENO, 2014, p. 187).

Neste norte, Estefânia Barboza (2014) afirma que o Poder Judiciário deve assumir um novo papel no que tange a efetivação dos direitos humanos, no sentido de que seja possibilitado um paradigma de segurança que não esteja limitado pelo texto, afinal a norma não está no texto abstratamente previsto, mas sim, no caso concreto posto à apreciação do Judiciário. Sendo assim, a segurança jurídica deve estar presente durante todo o processo jurisdicional desenvolvido, evitando que as decisões judiciais sejam realizadas por pressões políticas ou de forma consequencialista.

A reprodução inconsequente de decisões pela mera agilização das demandas processuais reforça a crítica externada por Humberto Theodoro Júnior (2006, p. 15) quando afirma que "urge, pois, evitar a consumação da morte do direito, restaurando e conservando sua essência: a segurança jurídica"

Rompe-se com a visão normativa legalista para assumir um paradigma consubstanciado no direito fundamental principiológico o que repercute diretamente na concepção de segurança jurídica, "que deixa de ser estática, na medida em que passa a conviver com um direito muito mais flexível e menos rígido" (OLIVEIRA, 2008, p. 19). 
Dessa forma, deve-se buscar a segurança jurídica como elemento natural e necessário a todo Estado de Direito Democrático, cuja relação com o ideal de justiça manifesta a complementariedade estruturante do Estado de Direito, cabendo, para além de aplicar o direito de forma uniforme e isonomicamente ante situações semelhantes (TERRA, 2010, p. 125) promover a efetiva aplicação do Direito.

\section{CONSIDERAÇÕES FINAIS}

Conforme o estudo alhures realizado, cumpre tecer algumas considerações finais acerca da temática interligada da segurança jurídica, da jurisdição e da efetividade do direito.

De tal modo, tem-se que a noção de segurança jurídica se encontra vinculada à própria compreensão do Estado contemporâneo, uma vez que este trabalha com a imprescindibilidade da observância dos ditames constitucionais, principalmente dos direitos humanos fundamentais, na qual se insere o referido direito.

Ademais, é possível afirmar que a segurança jurídica, enquanto vertente do conceito amplo da segurança previsto na esfera constitucional e em documentos internacionais, prediz ao sistema jurisdicional a necessidade de certeza e previsibilidade, constando, portanto, no ordenamento jurídico brasileiro enquanto um direito fundamental, cuja observância e concretização são cogentes.

Nesse sentido, relevância ímpar ganha a prestação da tutela jurisdicional quando realiza sua atividade típica, pois deverá, para além de observar a segurança jurídica, também, efetivá-la.

Para tanto, as decisões judiciais não podem ser realizadas de forma mecânica, aplicando a letra da lei a despeito de qualquer busca pela justiça, ou seja, para além de aplicar o direito de forma uniforme diante de situações semelhantes, deve o Poder Judiciário promover a efetiva aplicação do Direito dentro de um contexto temporal. Assim sendo, ultrapassa-se a ideia de que conferir segurança jurídica e proferir decisões semelhantes a fim de atingir a própria essência e efetividade do direito por meio da tutela jurisdicional.

Deste modo, a finalidade basilar da segurança jurídica, enquanto um direito fundamental estruturante do Estado Constitucional, está na consecução da efetividade da jurisdição e do Direito em si no momento em que exige do Poder Judiciário decisões atentas a legislação, mas principalmente, sensíveis a cada caso concreto apresentado a sua apreciação. 


\section{REFERÊNCIAS}

ÁVILA, Humberto. Segurança Jurídica: entre permanência, mudança e realização no direito tributário. São Paulo: Malheiros, 2012.

AMARAL, Guilherme Rizzo. Efetividade, segurança, massificação e a proposta de um "incidente de resolução de demandas repetitivas". In: Revista de Processo. Vol. 196/2011. p. 237 - 274. Jun/2011.

BARBOZA, Estefânia Maria de Queiroz. Precedentes judiciais e segurança jurídica: fundamentos e possibilidades para a jurisdição constitucional brasileira. São Paulo: Saraiva, 2014.

BRASIL. Constituição da República Federativa do Brasil de 1988. Disponível em: <http://www.planalto.gov.br/ccivil_03/constituicao/constituicaocompilado.htm> Acesso em 07 ago. 2016.

CAMBI, Eduardo; BUENO, Filipe Braz da Silva. Segurança jurídica e efetividade processual. In: Revista dos Tribunais Sul;| vol. 4/2014; p. 175 - 190; Mar - Abr / 2014.

CANOTILHO, J. J. Gomes. Direito Constitucional. 5. ed. Coimbra: Almedina, 1992.

Constituição dirigente e vinculação do legislador: contributo para a compreensão das normas constitucionais programáticas. Coimbra: Coimbra Editora, 1994.

Direito constitucional e teoria da constituição. 7. ed. Coimbra: Almedina, 2003.

CONVENÇÃO AMERICANA DOS DIREITOS HUMANOS. 1969. Disponível em: < http://www.pge.sp.gov.br/centrodeestudos/bibliotecavirtual/instrumentos/sanjose.htm> Acesso em: 07 ago. 2016.

COMPARATO, Fábio Konder. A afirmação histórica dos direitos humanos. 5. ed. ver. e atual. São Paulo: Saraiva, 2007.

CUNHA JR., Dirley. Curso de direito constitucional. 7. ed. Salvador: JusPoivm, 2013.

DECLARAÇÃO UNIVERSAL DOS DIREITOS HUMANOS. 1948. Disponível em: <http://www.unicef.org/brazil/pt/resources_10133.htm> Acesso em: 07 ago. 2016.

DELOS, Joseph T.. Le but du droit: bien commun, justice, sécurité. Paris: Recuiel Sirey, 1938.

MITIDIERO, Daniel. Cortes Superiores e Cortes Supremas: Do controle à interpretação da jurisprudência ao precedente. São Paulo: Revista dos Tribunais, 2013.

MORAES, Alexandre de. Direitos humanos fundamentais: teoria geral, comentários aos arts. $1^{0}$ ao $5^{0}$ da Constituição Federal da República federativa do Brasil, doutrina e jurisprudência. 9. ed. São Paulo: Atlas, 2011.

OLIVEIRA, Carlos Alberto Álvaro de. O processo civil na perspectiva dos direitos fundamentais. Disponível em: < file:///C:/Users/Raquel/Downloads/49187-199540-1-PB.pdf> Acesso em 22 set. 2016.

O formalismo-valorativo em confronto com o formalismo excessivo. In: Revista da Faculdade de Direito da Universidade de Lisboa. vol. XLVII. n. 1 e 2. p. 253-277. Lisboa, 2006.

Os direitos fundamentais à efetividade e à segurança em perspectiva dinâmica. In: Revista de Processo.| Vol. 155/2008. p. 11 - 26. Jan / 2008. 
PARGA, Milagros Otero. Valores constitucionales: introducción a la Filosofía del Derecho: Axiología jurídica. Santiago de Compostela: Universidade, 1999.

PECES-BARBA, Gregorio. La seguridad jurídica desde la filosofia del derecho. In: Anuario de Derechos Humanos, $\mathrm{n}^{\mathrm{o}}$. 6. Madrid: Universidad Complutense, 1990. Dispoível em: < http://earchivo.uc3m.es/bitstream/handle/10016/10384/seguridad_Peces_ADH_1990.pdf?sequence=1\&isAllowed=y > Acesso em 08 set. 2016.

PÉREZ LUÑO, Antonio Enrique. Los derechos fundamentales. 10.ed. Madrid: Tecnos, 2011.

Derechos humanos, Estado de derecho y Constitucion. 6. Ed. Madrid: 1999.

La seguridad jurídica: una garantía del derecho y la justicia. In: Boletín de la Facultad de Derecho, nº. 15, 2000. Disponível em: < http://e-spacio.uned.es/fez/eserv/bibliuned:BFD-2000-15-48A09575/PDF> Acesso em: 07 set. 2016.

REALE, Miguel. Teoria Tridimensional do Direito. 5. ed. São Paulo: Saraiva, 1994.

RUBIN, Fernando. Efetividade versus segurança jurídica: cenários de concretização dos dois macroprincípios processuais no novo CPC. In: Revista Bonijuris. Outubro/2015. Ano XXVII, n. 623, v. 27, n. 10

SARLET. Ingo Wolfgang. A eficácia dos direitos fundamentais. 7. ed. rev. atual. e ampl.. Porto Alegre: Livraria dos Advogados, 2007.

A Eficácia do Direito Fundamental à Segurança Jurídica: dignidade da pessoa humana, direitos fundamentais e proibição de retrocesso social no direito constitucional brasileiro. In: Revista Páginas de Direito, Porto Alegre, ano 6, $\mathrm{n}^{\mathrm{o}} 371, \quad 2006 . \quad$ Disponível <http://www.tex.pro.br/images/stories/PDF_artigos/aeficacia_ingo_wlfgang_sarlett.pdf> Acesso em 07 ago. 2016.

; MARINONI, Luiz Guilherme; MITIDIERO, Daniel. Curso de direito constitucional. São Paulo: RT, 2014.

SILVA, José Afonso da. Curso de direito constitucional positivo. São Paulo: Malheiros, 2005.

TERRA, Marcelo. Segurança jurídica e atividade imobiliária. In: GERMANOS, Paulo André Jorge (coord.). Segurança jurídica. Coletânea de textos. Rio de janeiro: Elsevier, 2010.

THEODORO JR., Humberto; FARIA, Juliana Cordeiro de. A coisa julgada inconstitucional e os instrumentos processuais para seu controle. In: Revista Síntese de Direito Civil e Processual Civil. n. 19. Porto Alegre, 2002.

. A onda reformista do direito positivo e suas implicações com o princípio da segurança jurídica. In: Revista de Processo, vol. 136/2006. p. 32-57; Jun/2006.

WIVIURKA, Eduardo Seino. A legitimidade procedimental a partir de Jürgen Habermas como forma de fortalecimento da esfera pública através da participação popular. Dissertação (Mestrado em Direito).. 